\title{
Activation of peroxisome proliferator-activated receptor- $\gamma$ by curcumin blocks the signaling pathways for PDGF and EGF in hepatic stellate cells
}

\author{
Jianguo Lin and Anping Chen
}

During hepatic fibrogenesis, reduction in the abundance of peroxisome proliferator-activated receptor- $\gamma$ (PPAR $\gamma$ ) is accompanied by activation of mitogenic signaling for platelet-derived growth factor (PDGF) and epidermal growth factor (EGF) in hepatic stellate cells (HSCs), the major effector cells. We previously reported that curcumin, the yellow pigment in curry, interrupted PDGF and EGF signaling, stimulated PPAR $\gamma$ gene expression, and enhanced its activity, leading to inhibition of cell proliferation of activated HSC in vitro and in vivo. The aim of this study was to elucidate the underlying mechanisms. We hypothesized that the enhancement of PPAR $\gamma$ activity by curcumin might result in the interruption of PDGF and EGF signaling. Our experiments demonstrated that curcumin, with different treatment strategies, showed different efficiencies in the inhibition of PDGF- or EGF-stimulated HSC proliferation. Further experiments observed that curcumin dose dependently reduced gene expression of PDGF and EGF receptors (ie, PDGF- $\beta$ R and EGFR), which required PPAR $\gamma$ activation. The activation of PPAR $\gamma$ by its agonist suppressed $p d g f-\beta r$ and egfr expression in HSC. In addition, curcumin reduced the phosphorylation levels of PDGF- $\beta$ R and EGFR, as well as their downstream signaling cascades, including ERK1/2 and JNK1/2. Moreover, activation of PPAR $\gamma$ induced gene expression of glutamate-cysteine ligase, the rate-limiting enzyme in de novo synthesis of the major intracellular antioxidant, glutathione. De novo synthesis of glutathione was required for curcumin to suppress $p d g f-\beta r$ and egfr expression in activated HSCs. Our results collectively demonstrated that enhancement of PPAR $\gamma$ activity by curcumin interrupted PDGF and EGF signaling in activated HSCs by reducing the phosphorylation levels of PDGF- $\beta$ R and EGFR, and by suppressing the receptor gene expression. These results provide novel insights into the mechanisms of curcumin in the inhibition of HSC activation and the suppression of hepatic fibrogenesis.

Laboratory Investigation (2008) 88, 529-540; doi:10.1038/labinvest.2008.20; published online 10 March 2008

KEYWORDS: hepatic fibrosis; hepatic stellate cell; oxidative stress; signaling pathways; gene expression

Hepatic stellate cells (HSCs) are recognized as the major effector cells in the development of hepatic fibrosis. ${ }^{1,2}$ In response to liver injury caused by virus, chemicals, autoimmune reactions, or metabolic disorders, HSCs undergo obvious phenotypic alterations from a state of quiescence to activation. ${ }^{1,2}$ HSC activation is characterized by enhanced cell proliferation, over-production of extracellular matrix (ECM), and de novo synthesis of $\alpha$-smooth muscle actin. This process is coupled with the up-expression of receptors for plateletderived growth factor (PDGF) ${ }^{3}$ and epidermal growth factor (EGF), ${ }^{4-6}$ as well as the dramatic down-expression of peroxisome proliferator-activated receptor- $\gamma(\operatorname{PPAR} \gamma) .^{7-9}$ The alteration in $\operatorname{PPAR} \gamma$ activity plays an important role in HSC activation. ${ }^{10,11}$ HSC proliferation is, in a receptor-dependent manner, triggered by autocrine/paracrine activation of the signaling for mitogenic growth factors, including PDGF and EGF. $^{4,12}$ Both PDGF- $\beta$ R and EGF receptor (EGFR) contain intrinsic tyrosine kinase activity. Upon binding to their ligands, the receptors become phosphorylated at the tyrosine residues, leading to activation of their downstream cascades, including the extracellular signal-regulated kinase (ERK) and the Jun N-terminal kinase (JNK). ${ }^{13,14}$

In the last decade, advances in the understanding of genes promoting HSC activation have been impressive. There are, however, few breakthroughs in the therapeutic intervention of hepatic fibrogenesis. Therefore, research identifying

Department of Pathology, School of Medicine, Saint Louis University, St Louis, MO, USA

Correspondence: Dr A Chen, PhD, Department of Pathology, School of Medicine, Saint Louis University, 1100 S. Grand Blvd, Edward A. Doisy Research Center, St Louis, MO 63104, USA. E-mail: achen5@slu.edu

Received 04 January 2008; revised 07 February 2008; accepted 10 February 2008 
antifibrogenic agents that are innocuous is of high priority and is urgently needed. Most evolving antifibrogenic therapies will be aimed at inhibiting HSC activation. The antioxidant curcumin is the yellow pigment in the curry from turmeric. It has received attention as a promising dietary supplement for the treatment of hepatic fibrogenesis. ${ }^{11,15-22}$ We previously reported that curcumin interrupted PDGF and EGF signaling, stimulated gene expression of $\operatorname{PPAR} \gamma$, and enhanced its activity, leading to inhibition of cell proliferation of activated HSCs in vitro. ${ }^{11,22}$ The aim of this study was to elucidate the underlying mechanisms. We hypothesized that enhancement of PPAR $\gamma$ activity by curcumin might result in interruption of the signaling pathways for PDGF and EGF. Results in this report support our hypothesis and provide novel insights into the mechanisms of curcumin in the inhibition of HSC activation and the suppression of hepatic fibrogenesis.

\section{MATERIALS AND METHODS Materials and Chemicals}

Curcumin (purity > 94\%) was purchased from Sigma (St Louis, MO, USA) and dissolved in $100 \%$ ethanol. 15 -Deoxy- $\Delta^{12,14}$ prostaglandin $\mathrm{J}_{2}\left(\mathrm{PGJ}_{2}\right)$, a natural PPAR $\gamma$ agonist, is the product of Cayman Chemical Company (Ann Arbor, MI, USA). PD98059 (an ERK inhibitor) and SP600125 (a JNK inhibitor) were, respectively, purchased from Biomol Research Labs. Inc (Plymouth Meeting, PA, USA) and Sigma, both of which were dissolved in DMSO. PD68235, a specific PPAR $\gamma$ antagonist, was generously provided by Pfizer (Ann Arbor, MI, USA). L-Buthionine-sulfoximine (BSO) and $N$-acetyl-L-cysteine (NAC) were obtained from Sigma. Recombinant PDGF-BB and EGF were purchased from Cell Sciences (Canton, MA, USA).

\section{Isolation and Culture of HSCs}

HSCs were isolated from male Spague-Dawley rats (200$250 \mathrm{~g}$ ) by the pronase-collagenase perfusion in situ prior to density gradient centrifugation on an Opti-Prep ${ }^{\mathrm{TM}}$ gradient, as previously described. ${ }^{23}$ Primary cells were cultured in Dulbecco's modified Eagle's medium (DMEM) supplemented with $20 \%$ fetal bovine serum (FBS). The passaged cells were grown in DMEM with $10 \%$ of FBS. Semi-confluent HSCs with 4-8 passages were used for the experiments. In some of the experiments, cells were serum-starved for $24 \mathrm{~h}$ in DMEM with $0.5 \%$ of FBS before treatment.

\section{Determination of Cell Proliferation}

HSCs were serum-starved in DMEM with $0.5 \%$ of FBS for $24 \mathrm{~h}$ prior to addition of PDGF or EGF at the indicated doses, in the presence or absence of curcumin $(20 \mu \mathrm{M})$, for an additional $24 \mathrm{~h}$. In another group, HSCs were pretreated with curcumin $(20 \mu \mathrm{M})$ for $24 \mathrm{~h}$ in DMEM with $0.5 \%$ of FBS prior to addition of PDGF, or EGF, at the indicated doses for an additional $24 \mathrm{~h}$. Cell proliferation was determined either by counting cell numbers using a computer-equipped cell counter (Coulter Corporation, Miami, FL, USA), or using the CellTiter $96^{\circledR}$ aqueous non-radioactive cell proliferation assay kit (ie, MTS assays) purchased from Promega, according to the manufacturer's instructions. MTS assay is a colorimetric method for determining the number of viable cells. Each treatment was performed in triplicates and was repeated for at least three times.

\section{Western Blotting Analyses}

Whole-cell extracts were prepared as described. ${ }^{23}$ Proteins were separated by SDS-PAGE with 10\% of resolving gel and transferred to a PVDF membrane. The target proteins were respectively recognized by primary antibodies against phosphorylated types of PDGF- $\beta$ R, EGFR, ERK1/2, or JNK1/2 and the corresponding non-phosphorylated proteins, and subsequently detected by horseradish peroxidase-conjugated secondary antibodies (Santa Cruz Biotechnology, Santa Cruz, CA, USA). Protein bands were visualized with a chemiluminescence reagent (Amersham Biosciences, Piscataway, NJ, USA). In western blotting analyses, the densities of bands were normalized with the internal invariable control, $\beta$-actin.

\section{RNA Isolation and Real-time Polymerase Chain Reaction} Total RNA was extracted using TRI reagent ${ }^{\circledR}$ (Sigma), following the protocol provided by the manufacturer. Real-time polymerase chain reaction (PCR) was carried out as previously described. ${ }^{11}$ mRNA fold changes of target genes relative to endogenous glyceraldehyde-3-phosphate dehydrogenase (GAPDH) control were calculated as suggested by Schmittgen et al. ${ }^{24}$ The following primers were used for real-time PCR: PDGF- $\beta$ R: (F) $5^{\prime}$-CTGCCACAGCATGATGAGGATTGA- $3^{\prime}$, (R) 5'-GCCAGGATGGCTGAGATCACCAC; EGFR: (F) 5'-GTGAC CGTTTGGGAGTTGATGA-3', (R) 5'-GGCTGAGGGAGGCGT TCTC-3'; GCLc: (F) 5'-TGTGTGATGAGCCCAAGGAC-3', (R) 5'-AGTTGGCTCGCATCATAGTTG-3'; GCLm: (F) 5'-CTGCT AAACTGTTCATTGTAG-3', (R) 5'-CTATGGGTTTTACCTGT G-3'; and GAPDH: (F) 5'-GGCAAATTCAACGGCACAGT-3', (R) 5'-AGATGGTGATGGGCTTCCC-3'.

\section{Plasmids and Transient Transfection Assays}

The $p d g f-\beta r$ promoter report plasmid, pPDGF- $\beta$ R-Luc, was a gift from Dr Keiko Funa (Ludwig Institute for Cancer Research, Uppsala, Sweden). It contained a fragment (1366 bp) of PDGF- $\beta$ R gene promoter subcloned into the luciferase expression vector pGL2 (basic). ${ }^{25}$ The egfr promoter luciferase reporter plasmid contained a fragment (1109 bp) of egfr promoter in a luciferase reporter plasmid. It was a gift from Dr Alfred C Johnson (Laboratory of Molecular Biology, NCI/NIH, Bethesda, MD, USA). ${ }^{26}$ The cDNA-expressing plasmid, pPPAR $\gamma \mathrm{cDNA}$, contained a full fragment of cDNA encoding human PPAR $\gamma$ (a gift from Dr Reed Graves, Department of Medicine, University of Chicago, Chicago, IL, USA). The plasmid pdn-ERK, or pdnJNK, contained a full length of cDNA fragment encoding the dominant-negative form of ERK or JNK, respectively. Both of them were previously described and used. ${ }^{27}$ The plasmid 
pa-ERK, or pa-JNK, contained a full length of cDNA fragment encoding the constitutively active form of ERK, or JNK, respectively. ${ }^{27,28}$ Transient transfection assays were performed using Lipofectamine ${ }^{\circledR}$ (Life Technologies) following the protocol provided by the manufacturer. A total of $3.5 \sim 4.5 \mu \mathrm{g}$ of DNA were added to semi-confluent cells in each well of six-well plastic plates. Transfection efficiency was controlled by co-transfection of the $\beta$-galactosidase reporter plasmid, pSV- $\beta$-gal ( $0.5 \mu \mathrm{g} /$ well) (Promega). $\beta$-Galactosidase activity was measured using an assay kit from Promega Corp. Luciferase activities were expressed as relative unit after normalization with $\beta$-galactosidase activity. Results were combined from multiple independent experiments $(n \geq 6)$ and were presented as means \pm s.d.

\section{Statistical Analysis}

Differences between means were evaluated using an unpaired two-sided Student's $t$-test $(P<0.05$ was considered significant). Where appropriate, comparisons of multiple treatment conditions with control were analyzed by ANOVA with Dunnett's test for post hoc analysis.

\section{RESULTS}

Curcumin, with Different Treatment Strategies, showed Different Efficiencies in the Inhibition of PDGF- or EGF-Stimulated HSC Proliferation

PDGF and EGF have been identified as the most potent stimuli for proliferation of HSCs. ${ }^{4,12}$ To evaluate the effect of curcumin on the PDGF-, or EGF-stimulated cell proliferation, cultured HSCs were divided into three groups. In the first two groups, HSCs were serum-starved in DMEM with $0.5 \%$ of FBS for $24 \mathrm{~h}$ prior to addition of PDGF or EGF at the indicated doses in the simultaneous presence or absence of curcumin $(20 \mu \mathrm{M})$ for an additional $24 \mathrm{~h}$. In the third group, HSCs were pretreated with curcumin $(20 \mu \mathrm{M})$ for $24 \mathrm{~h}$ in DMEM with $0.5 \%$ of FBS prior to addition of PDGF, or EGF, at the indicated doses for an additional $24 \mathrm{~h}$. Cell proliferation was determined following these steps. As shown in Figure 1, in MTS assays exogenous PDGF or EGF caused, as expected, a dose-dependent increase in cell density (the left first columns in each group). The stimulatory effects of PDGF and EGF were diminished by curcumin (the middle and right columns in each group). However, the extent of diminution was obviously different when different strategies were used. Compared with simultaneous treatment with curcumin (the middle black columns), pretreatment with curcumin (the right blank columns) potentiated its role in the suppression of cell proliferation. For instance, compared with treatment with only PDGF at 15 or $20 \mathrm{ng} / \mathrm{ml}$, simultaneous treatment with curcumin $(20 \mu \mathrm{M})$ inhibited PDGFstimulated cell proliferation by 10 or $19 \%$, respectively (Figure 1a). However, pretreatment with curcumin $(20 \mu \mathrm{M})$ potentiated the inhibitory effect on PDGF-stimulated cell proliferation by 32 or $43 \%$, respectively (Figure 1a). Similar results were observed in EGF-stimulated cell proliferation when different treatment strategies with curcumin were used (Figure 1b). It bears notice that because experiments were performed in serum-depleted medium, even stimulated with PDGF or EGF, the rate of cell proliferation was relatively low, compared with that of cells grown in DMEM with $10 \%$ of FBS. Similar results were obtained using an alternative approach, that is, counting cell numbers using a computerequipped cell counter (data not shown here). Taken together, these results demonstrated that curcumin, with different
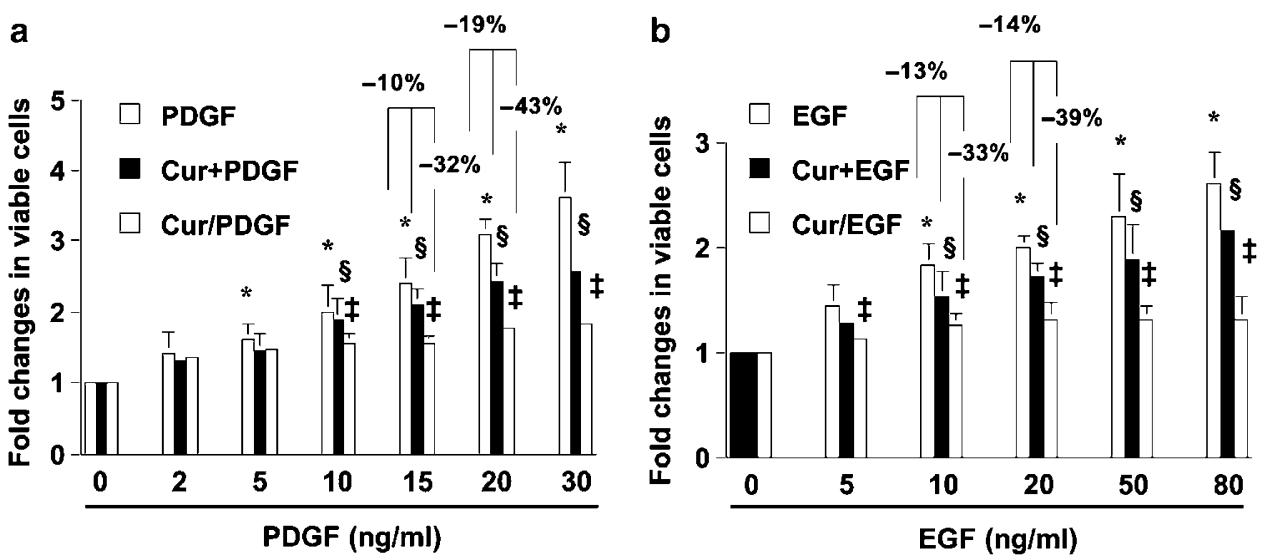

Figure 1 Curcumin, with different treatment strategies, showed different efficiencies in the inhibition of PDGF- or EGF-stimulated HSC proliferation. Cultured HSCs were divided into three groups. In the first two groups, HSCs were serum-starved in DMEM with $0.5 \%$ of FBS for $24 \mathrm{~h}$ prior to addition of PDGF (a) or EGF (b) at the indicated doses in the simultaneous presence (Cur + PDGF, or Cur + EGF) or absence (PDGF or EGF) of curcumin (20 $\mu \mathrm{M}$ ) for an additional $24 \mathrm{~h}$. In the third group, HSCs were pretreated with curcumin $(20 \mu \mathrm{M})$ for $24 \mathrm{~h}$ in DMEM with $0.5 \%$ of FBS prior to the addition of PDGF (a) or EGF (b) at the indicated doses for an additional $24 \mathrm{~h}$ (Cur/PDGF, or Cur/EGF). Cell proliferation was determined by colorimetric MTS assays. Results were expressed as fold changes in the number of viable cells, compared with the untreated control (the first columns on the left). Values were expressed as means \pm s.d. $(n=3)$. ${ }^{\star} P<0.05$ vs the untreated control (the first column on the left). ${ }^{\circledR} P<0.05$ vs cells treated with PDGF or EGF only (the left first column in the same group). ${ }^{\ddagger} P<0.05$ vs cells simultaneously treated with curcumin plus PDGF or EGF (Cur + PDGF, or Cur + EGF) (the middle column in the same group). 
treatment strategies, showed different efficiencies in the inhibition of PDGF- or EGF-stimulated HSC proliferation. The intriguing observations urged us to investigate the underlying mechanisms.

\section{Curcumin Inhibited Gene Expression of PDGF $\beta$ R and EGFR in Activated HSCs In Vitro, which Might Require Activation of PPAR $\gamma$}

Because PDGF and EGF signaling is receptor-dependent, we proposed that the different inhibitory efficacy of curcumin on cell proliferation might result, at least partially, from suppression of gene expression of their receptors in the case of pretreatment. The effect of curcumin on gene expression of PDGF- $\beta$ R and EGFR in passaged HSCs was, therefore, evaluated. Pre-confluent HSCs in six-well culture plates were transiently transfected with the $p d g f-\beta r$ promoter luciferase reporter plasmid, pPDGF- $\beta$ R-Luc, or the egfr promoter luciferase reporter plasmid, pEGFR-Luc. After recovery, cells were treated with curcumin at various concentrations as indicated for $24 \mathrm{~h}$. As shown in Figure 2a, in luciferase assays curcumin caused a dose-dependent reduction in luciferase activity, suggesting that curcumin might reduce the promoter activity of PDGF- $\beta$ R and EGFR genes in activated HSCs in vitro. To confirm the result, passaged HSCs were treated with curcumin at various concentrations as indicated for $24 \mathrm{~h}$. Real-time PCR (Figure 2b) and Western blotting analyses (Figure 2c) demonstrated that curcumin significantly reduced the mRNA levels and the protein abundance of PDGF- $\beta$ R and EGFR in a dose-dependent manner. These results demonstrated that curcumin suppressed $p d g f-\beta r$ and egfr expression in activated HSCs in vitro.

We previously reported that curcumin induced gene expression of PPAR $\gamma$ and enhanced its activity in cultured HSCs, ${ }^{11}$ which was a prerequisite for curcumin to inhibit HSC proliferation and to suppress gene expression of ECM components. ${ }^{11,19}$ It was, therefore, plausible to further postulate that inhibition of $p d g f-\beta r$ and egfr expression by curcumin might be mediated by activation of PPAR $\gamma$. To test the postulation, cultured HSCs were pretreated with or without PD68235 $(20 \mu \mathrm{M})$, a specific PPAR $\gamma$ antagonist, for $1 \mathrm{~h}$ prior to addition of curcumin $(20 \mu \mathrm{M})$ for an additional $24 \mathrm{~h}$. Gene expression of PDGF $\beta$ R and EGFR was assessed by real-time PCR (Figure 2b) and Western blotting analyses (Figure 2c). It was revealed that pre-exposure of HSCs to PD68235 obviously diminished the inhibitory effect of curcumin on $p d g f-\beta r$ and egfr expression in activated HSCs in vitro, suggesting that activation of $\operatorname{PPAR} \gamma$ might be necessary for curcumin to inhibit $p d g f-\beta r$ and egfr expression.

\section{Activation of PPAR $\gamma$ Suppressed pdgf- $\beta r$ and egfr Expression in Activated HSCs In Vitro}

Additional experiments were performed to verify the role of $\operatorname{PPAR} \gamma$ in curcumin suppression of $p d g f-\beta r$ and egfr expression. HSCs in six-well culture plates were co-transfected with a total of $4.5 \mu \mathrm{g}$ of a DNA mixture per well, including $2 \mu \mathrm{g}$
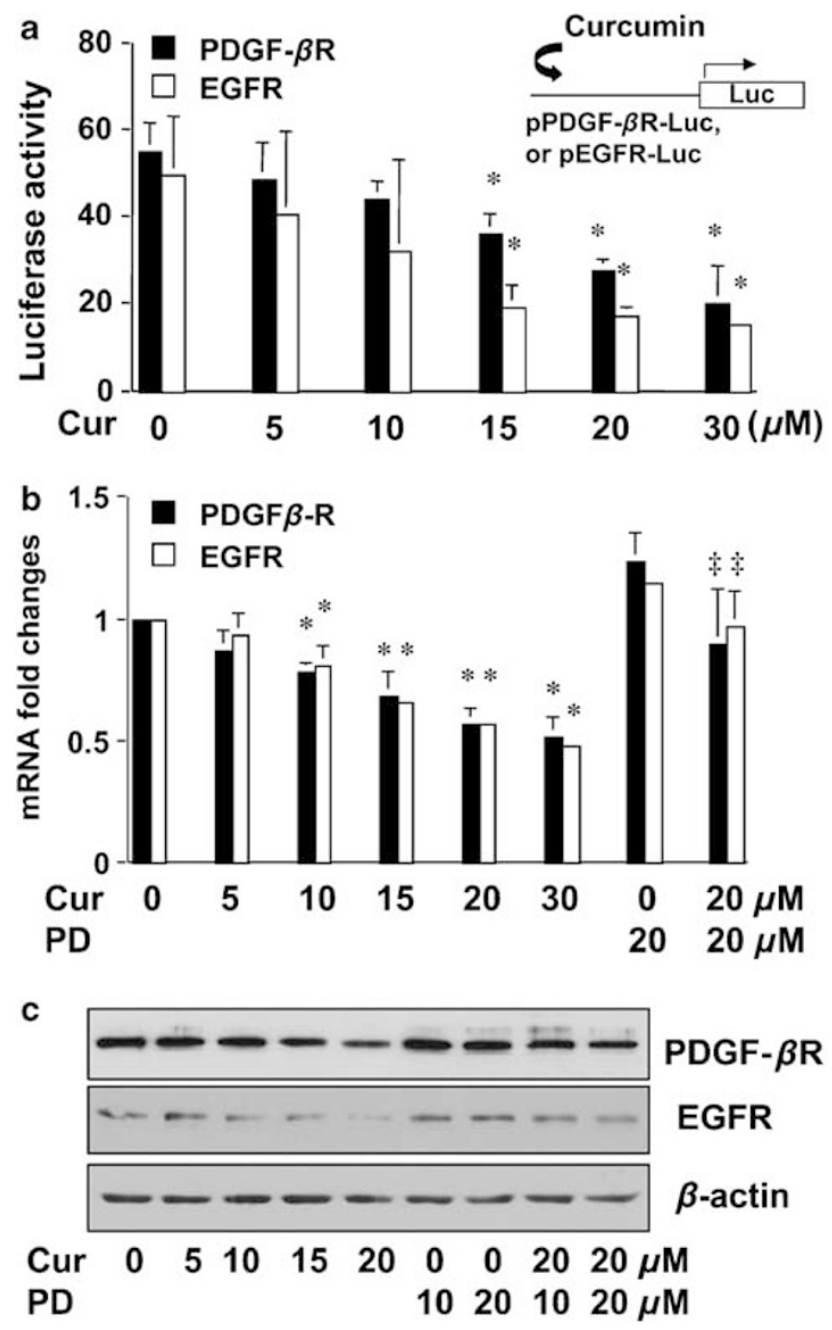

Figure 2 Curcumin dose dependently suppressed gene expression of PDGF- $\beta$ R and EGFR in cultured HSCs, which might require activation of PPAR $\gamma$. Cultured HSCs in DMEM with $10 \%$ of FBS were pretreated with or without the PD68235 $(20 \mu \mathrm{M})$, a specific PPAR $\gamma$ antagonist, for $1 \mathrm{~h}$ prior to the addition of curcumin at the indicated concentrations for an additional $24 \mathrm{~h}$. (a) Luciferase assays of cells transfected with pPDGF- $\beta$ R-Luc, or pEGFR-Luc. Luciferase activities were expressed as relative units after $\beta$-galactosidase normalization $(n=6)$. ${ }^{*} P<0.05$ vs the untreated control (the corresponding first column on the left). The floating schema denoted the pPDGF- $\beta$ R-Luc, or pEGFR-Luc, luciferase reporter construct in use and the application of curcumin to the system; (b) real-time PCR analyses of the mRNA levels of PDGF- $\beta$ R or EGFR. GAPDH was used as an invariant control for calculating fold changes of target mRNA $(n=3)$. ${ }^{\star} P<0.05$ vs the untreated control (the corresponding first column on the left); ${ }^{\ddagger} P<0.05$ vs cells treated with curcumin at $20 \mu \mathrm{M}$; (c) Western blotting analyses of the protein abundance of PDGF- $\beta$ R or EGFR. $\beta$-Actin was used as an invariant control for equal loading. Representative result is shown from three independent experiments.

of pPDGF- $\beta$ R-Luc, or pEGFR-Luc, $0.5 \mu \mathrm{g}$ of pSV- $\beta$-gal, and $2 \mu \mathrm{g}$ of the PPAR $\gamma$ cDNA expressing plasmid pPPAR $\gamma \mathrm{cDNA}$ at various doses plus the empty vector pcDNA. The latter was used to ensure equal amount of total DNA in transfection assays. After recovery, cells were treated with or without curcumin $(20 \mu \mathrm{M})$ in media containing FBS $(10 \%)$ for $24 \mathrm{~h}$. Luciferase activity assays in Figure 3 indicate that forced 


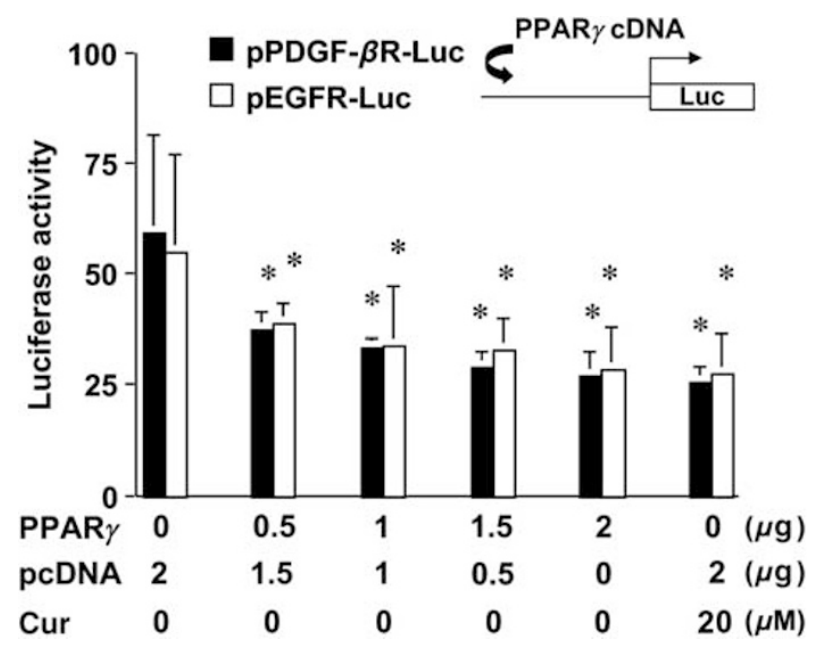

Figure 3 Forced expression of PPAR $\gamma$ reduced the promoter activity of PDGF- $\beta$ R and EGFR genes in passaged HSCs. HSCs in six-well culture plates in DMEM with $10 \%$ of FBS were co-transfected with a total of $4.5 \mu \mathrm{g}$ of a DNA mixture per well, including $2 \mu \mathrm{g}$ of pPDGF- $\beta$ R-Luc or pEGFR-Luc, $0.5 \mu \mathrm{g}$ of pSV- $\beta$-gal and $2 \mu \mathrm{g}$ of pPPAR $\gamma$ CDNA at various doses plus the empty vector pcDNA. The latter was used to ensure equal amount of total DNA in transfection assays. After recovery, cells were treated with or without curcumin $(20 \mu \mathrm{M})$ in media containing FBS $(10 \%)$ for $24 \mathrm{~h}$. Luciferase activities were expressed as relative units after $\beta$-galactosidase normalization $(n=6) .{ }^{*} P<0.05$ vs cells with no treatment (the first columns on the left). The floating schema denoted the pPDGF- $\beta$ R-Luc, or pEGFR-Luc, luciferase reporter construct in use and the application of the cDNA expressing plasmid pPPAR $\gamma$ CDNA to the system.

expression of exogenous PPAR $\gamma$ cDNA dose dependently reduced luciferase activity, indicating reduction in the promoter activity of PDGF- $\beta$ R and EGFR genes in cultured HSCs. The inhibitory effect of exogenous PPAR $\gamma$ cDNA was abrogated by treatment of cells with the PPAR $\gamma$ antagonist, PD68235 (data not shown here). Prior experiments have suggested that $10 \%$ FBS in the medium might contain enough agonists to activate PPAR $\gamma$ in HSCs. ${ }^{9,11,19,20}$

Additional experiments further confirmed that activation of endogenous $\mathrm{PPAR} \gamma$ by its natural agonist, $\mathrm{PGJ}_{2}$, inhibited $p d g f-\beta r$ and egfr promoter activity (Figure 4a), and reduced the mRNA level (Figure $4 \mathrm{~b}$ ) and protein abundance (Figure $4 \mathrm{c}$ ) of PDGF- $\beta$ R and EGFR in cultured HSCs. These results demonstrated that activation of PPAR $\gamma$ suppressed $p d g f-\beta r$ and egfr expression in activated HSCs in vitro. Taken together, our results implicated that inhibition of $p d g f-\beta r$ and egfr expression by curcumin might be mediated by activation of PPAR $\gamma$ in activated HSCs in vitro.

\section{Curcumin Reduced the Phosphorylation Levels of PDGF- $\beta$ R, EGFR, and of their Downstream Inter-Mediators in HSCs}

In addition to suppression of $p d g f-\beta r$ and egfr expression, curcumin might have additional mechanisms to interrupt the signaling pathways for PDGF and EGF in HSCs. Additional experiments were conducted to evaluate the effects of curcumin on the tyrosine phosphorylation of PDGF- $\beta$ R, EGFR,
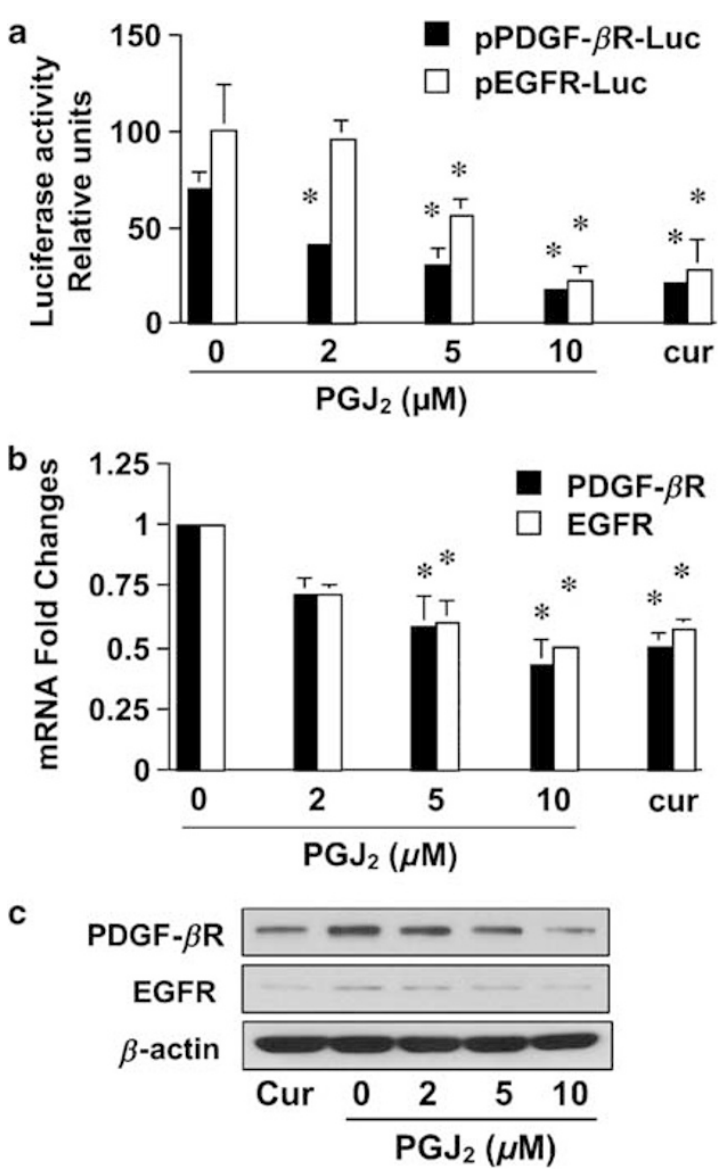

Figure 4 The activation of PPAR $\gamma$ by PGJ ${ }_{2}$ suppressed $p d g f-\beta r$ and egfr expression in activated HSCs in vitro. Cultured HSCs in DMEM with $10 \%$ of FBS were treated with curcumin $(20 \mu \mathrm{M})$ or $\mathrm{PGJ}_{2}$ at the indicated concentrations for $24 \mathrm{~h}$. (a) Luciferase assays of cells transfected with pPDGF- $\beta$ R-Luc, or pEGFR-Luc. Luciferase activities were expressed as relative units after $\beta$-galactosidase normalization $(n=6)$. ${ }^{*} P<0.05$ vs the untreated control (the corresponding 1st column on the left); (b) real-time PCR analyses of the mRNA levels of PDGF- $\beta$ R or EGFR. GAPDH was used as an invariant control for calculating fold changes of target mRNA $(n=3)$. ${ }^{\star} P<0.05$ vs the un-treated control (the corresponding 1 st column on the left); (c) Western blotting analyses of the abundance of PDGF- $\beta$ R or EGFR. $\beta$-Actin was used as an invariant control for equal loading. Representative result is shown from three independent experiments.

and their downstream cascades. Passaged HSCs were serumstarved in serum-depleted DMEM with $0.5 \%$ of FBS for $24 \mathrm{~h}$. Cells were stimulated with FBS (10\%) for various minutes, as indicated, with or without pretreatment with curcumin $(20 \mu \mathrm{M})$ for $1 \mathrm{~h}$. The phosphorylation levels of the target proteins were evaluated by Western blotting analyses. It is shown in Figure 5 that FBS rapidly stimulated tyrosine phosphorylation of PDGF- $\beta$ R and EGFR (well nos. 1, 3, 5, 7, and 9), leading to enhanced phosphorylation of the downstream inter-mediators ERK1/2 and JNK1/2, which reached their peaks within 10 20 min (well nos. 3 and 5). Pretreatment of cells with curcumin apparently reduced the phosphorylation levels of PDGF- $\beta$ R, EGFR, ERK1/2, and JNK1/2 (well nos. 2, 4, 6, 8, and 10), compared with their 
$\begin{array}{llllllllll}1 & 2 & 3 & 4 & 5 & 6 & 7 & 8 & 9 & 10\end{array}$

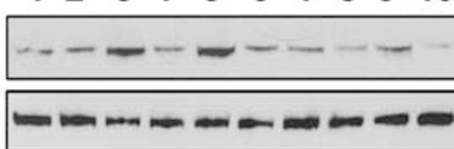

p-PDGF- $\beta R$

total PDGF- $\beta R$

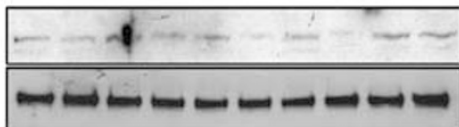

p-EGFR

total EGFR

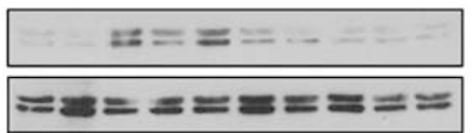

p-ERK1/2

total ERK1/2

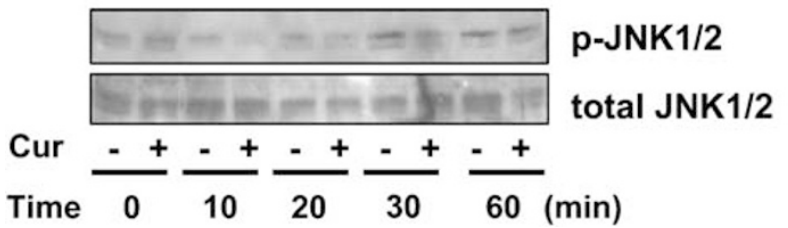

Figure 5 Curcumin reduced the phosphorylation levels of PDGF- $\beta$ R, EGFR, and downstream inter-mediators EKR and JNK in activated HSC in vitro. Serum-starved HSCs in DMEM with $10 \%$ of FBS were pretreated with or without curcumin at $20 \mu \mathrm{M}$ for $30 \mathrm{~min}$ prior to stimulation with FBS (10\%) for different lengths of time. Total protein extracts were prepared for detecting the levels of phosphorylated PDGF- $\beta$ R, EGFR, ERK, and JNK by Western blotting analysis. Total PDGF- $\beta$ R, EGFR, ERK, and JNK were used as the corresponding internal controls. Representative result is shown from three independent experiments.

corresponding counterparts (well nos. 1, 3, 5, 7, and 9). These results demonstrated that in addition to suppression of $p d g f-\beta r$ and egfr expression, curcumin interrupted the signaling pathways for PDGF and EGF in HSCs by reducing the phosphorylation levels of PDGF- $\beta$ R, EGFR, and their downstream inter-mediators.

\section{Inhibition of ERK or JNK Activity Resulted in Suppression of pdgf- $\beta r$ and egfr Expression in Activated HSCs In Vitro}

We assumed that inhibition of ERK and JNK activity by curcumin could result in suppression of $p d g f-\beta r$ and egfr expression in activated HSCs. Experiments were conducted to test the assumption. First experiments were performed to determine whether alteration of ERK or JNK activity could reduce the promoter activity of PDGF- $\beta$ R and EGFR genes in activated HSCs. HSCs were co-transfected with pPDGF- $\beta$ RLuc, or pEGFR-Luc, plus a cDNA expressing plasmid of pa-ERK, pa-JNK, pdn-ERK, or pdn-JNK. The cDNA expressing plasmid pa-ERK, or pa-JNK, contained a fragment of cDNA encoding the constitutively active form of ERK (a-ERK), or JNK (a-JNK), respectively. ${ }^{27,28}$ Similarly, the cDNA expressing plasmid pdn-ERK, or pdn-JNK, contained a fragment of cDNA encoding the dominant-negative form of ERK (dn-ERK) or JNK (dn-JNK), respectively. ${ }^{27,28}$ A total of $3.2 \mu \mathrm{g}$, or $4.5 \mu \mathrm{g}$, of plasmid DNA was used for co-transfection of HSCs in each well of six-well culture plates. It included $2 \mu \mathrm{g}$ of pPDGF- $\beta$ R-Luc, or pEGFR-Luc, $0.5 \mu \mathrm{g}$ of pSV-gal, and $0.7 \mu \mathrm{g}$ of pa-ERK or pa-JNK, or $2 \mu \mathrm{g}$ of pdn-ERK or pdn-JNK, plus the empty vector, pcDNA. The latter was used to ensure the equal amount of total DNA in co-transfection assays. After overnight recovery, cells were serum-starved in DMEM for $24 \mathrm{~h}$ prior to stimulation with FBS $(10 \%)$ in the presence or absence of curcumin $(20 \mu \mathrm{M})$ for an additional $24 \mathrm{~h}$. The effects of ERK or JNK activity on $p d g f-\beta r$ and egfr promoter activity were evaluated by luciferase assays. As shown in Figure 6a and c, compared with the untreated control (the corresponding first column on the left), activation of ERK, or JNK, by forced expression of pa-ERK, or pa-JNK, markedly increased luciferase activity (the second columns on the left). Curcumin significantly reduced, as expected, luciferase activity (the third columns on the left in Figure 6a and c). pa-ERK and pa-JNK dose dependently abolished the inhibitory effect of curcumin on luciferase activity (Figure 6a and c). In great contrast, inhibition of ERK or JNK by pdn-ERK or pdn-JNK dose dependently reduced luciferase activity (Figure $6 \mathrm{~b}$ and $\mathrm{d}$ ). These results collectively suggested that alteration of ERK or JNK activity regulated the promoter activity of PDGF- $\beta$ R and EGFR genes in activated HSCs in vitro.

Further experiments confirmed that inhibition of ERK, or JNK, by the ERK inhibitor, PD98059, or the JNK inhibitor, SP600125, mimicked the inhibitory effects of curcumin and reduced promoter activity (Figure $7 \mathrm{a}$ and $\mathrm{b}$ ), mRNA levels (Figure 7c and d), and protein abundance (Figure 7e and $\mathrm{f}$ ) of PDGF- $\beta$ R and EGFR in cultured HSCs, as demonstrated by co-transfection assays, real-time PCR, and western blotting analyses, respectively. Taken together, these results supported the assumption that inhibition of ERK and JNK activity by curcumin could result in suppression of $p d g f-\beta r$ and egfr expression in activated HSCs.

\section{De Novo Synthesis of GSH Played a Critical Role in Curcumin Inhibition of pdgf- $\beta r$ and egfr Expression in Activated HSCs}

We have previously demonstrated that curcumin dose, and time dependently attenuates oxidative stress in passaged HSCs, as demonstrated by scavenging of reactive oxygen species and reduction of lipid peroxidation. ${ }^{21}$ The antioxidant property of curcumin mainly results from increasing in the level of cellular glutathione (GSH) by induction of the activity and gene expression of glutamate-cysteine ligase (GCL), a rate-limiting enzyme in the synthesis of GSH, in activated HSCs in vitro. De novo synthesis of GSH is a prerequisite for curcumin to inhibit HSC activation. ${ }^{21}$ It was, therefore, plausible to investigate the role of the enhanced level of cellular GSH in the curcumin inhibition of $p d g f-\beta r$ and egfr expression in activated HSCs. Passaged HSCs were treated with curcumin $(20 \mu \mathrm{M})$, or NAC $(5 \mathrm{mM})$, a precursor of GSH by supplying cysteine, ${ }^{29}$ with or without the preexposure to BSO $(0.25 \mathrm{mM})$, a specific inhibitor of GCL to 

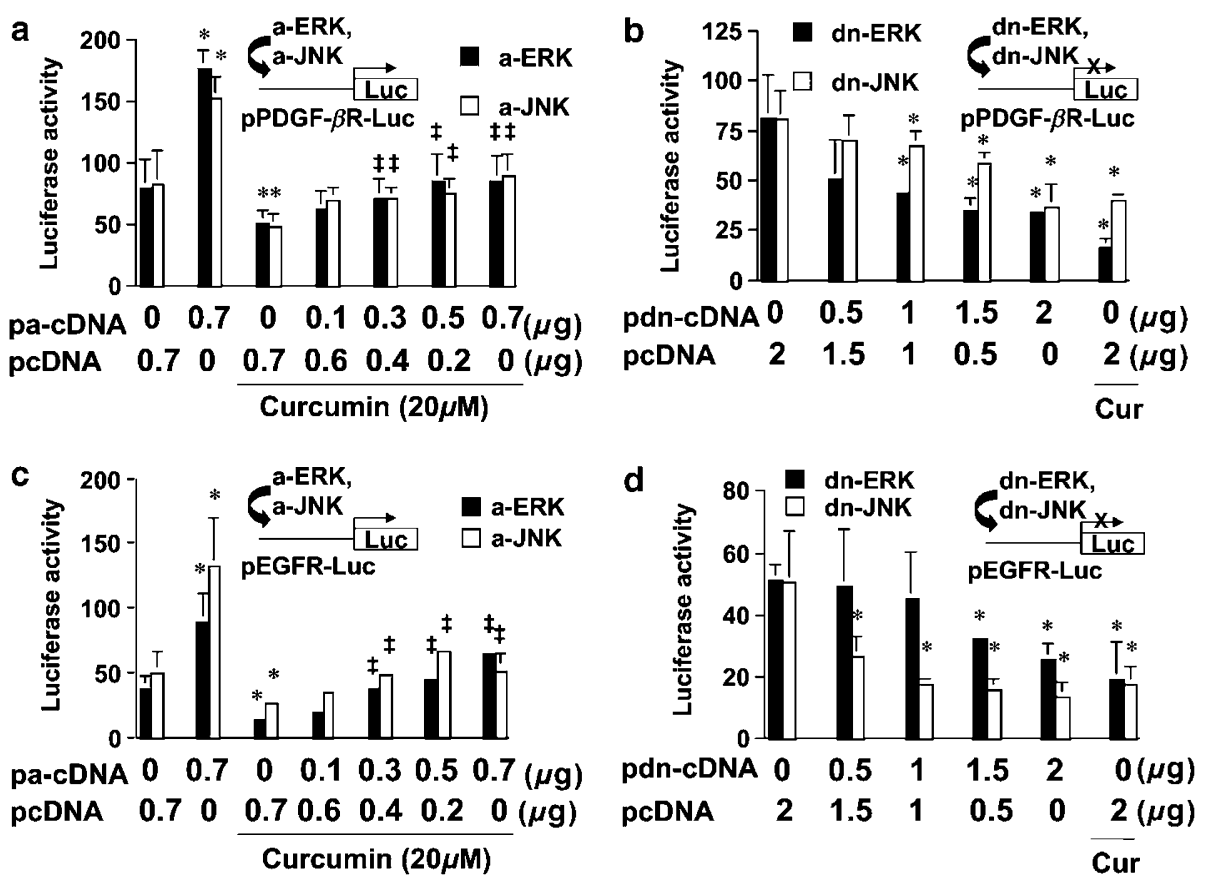

Figure 6 The alteration in ERK or JNK activity changed the promoter activity of PDGF- $\beta$ R and EGFR genes in activated HSCs in vitro. HSCs in six-well plates i $\mathrm{n}$ DMEM with $10 \%$ of FBS were co-tranfected with a fixed amount of a DNA mixture per well. It included $2 \mu \mathrm{g}$ of pPDGF- $\beta$ R-Luc (a and $\mathbf{b}$ ), or pEGFR-Luc (c and $\mathbf{d}$ ), $0.5 \mu \mathrm{g}$ of pSV- $\beta$-gal and a plasmid expressing the active form of pa-ERK, or pa-JNK (a and $\mathbf{c}$ ), or a plasmid expressing the dominant-negative form of pdn-ERK or pdn-JNK ( $\mathbf{b}$ and $\mathbf{d}$ ), plus the empty vector pcDNA. The latter was used to ensure equal amount of total DNA in transfection assays. The amount of DNA of pa-ERK, or pa-JNK, plus pcDNA was equalized to $0.7 \mu \mathrm{g}$ (a and $\mathbf{c}$ ). The amount of DNA of pdn-ERK, or pdn-JNK, plus pcDNA was equalized to $2 \mu \mathrm{g}$ (b and $\mathbf{d})$. After overnight recovery, cells were serum-starved in DMEM with $0.5 \%$ DMEM for $24 \mathrm{~h}$ prior to the stimulation with FBS $(10 \%)$ in the presence or absence of curcumin $(20 \mu \mathrm{M})$ for an additional $24 \mathrm{~h}$. Luciferase activities were expressed as relative units after $\beta$-galactosidase normalization $(n \geq 6)$. ${ }^{\star} P<0.05$ vs cells with no treatment (the corresponding first column on the left). ${ }^{\ddagger} P<0.05$ vs cells with curcumin only, without co-transfected pa-cDNA (the corresponding third column on the left). The floating schema denotes the pPDGF- $\beta$ R-Luc, or pEGFR-Luc, luciferase reporter construct in use and the application of a CDNA expressing plasmid to the system.

deplete cellular GSH, ${ }^{30}$ for $1 \mathrm{~h}$. As shown in Figure $8 \mathrm{a}$, in luciferase assays NAC, like curcumin, significantly reduced luciferase activity in HSCs transfected with pPDGF- $\beta$ R-Luc, or pEGFR-Luc. Pre-exposure of cells to BSO apparently diminished this inhibitory effect (the last two columns on the right side). This result suggested that de novo synthesis of GSH might reduce $p d g f-\beta r$ and egfr promoter activity in HSCs. Real-time PCR (Figure 8b) and Western blotting analyses (Figure 8c) further demonstrated that NAC, like curcu$\mathrm{min}$, reduced the mRNA levels and the protein abundance of PDGF- $\beta$ R and EGFR in activated HSCs. Pretreatment of cells with BSO abolished this inhibitory activity (the last two columns and wells on the right side of Figure $8 \mathrm{~b}$ and c). Taken together, these results demonstrated that de novo synthesis of GSH played a critical role in curcumin inhibition of $p d g f-\beta r$ and egfr expression in activated HSCs in vitro.

\section{Activation of PPAR $\gamma$ Induced gclc and $g$ clm Expression in Activated HSCs In Vitro}

We previously demonstrated that curcumin induced gene expression of PPAR $\gamma$ and enhanced its activity in HSCs. ${ }^{11}$ In addition, synthesis of GSH was required for curcumin suppression of $p d g f-\beta r$ and egfr expression in activated HSCs in vitro (Figure 8). To understand the underlying mechanisms, we assumed that the enhancement of PPAR $\gamma$ activity by curcumin might stimulate gene expression of the catalytic (GCLc) and modifier (GCLm) subunits of GCL, which could stimulate the synthesis of GSH and ultimately lead to suppression of $p d g f-\beta r$ and egfr expression. To test this assumption, passaged HSCs were pretreated with or without PD68235 $(20 \mu \mathrm{M})$, a specific PPAR $\gamma$ antagonist, for $30 \mathrm{~min}$ prior to addition of curcumin $(20 \mu \mathrm{M})$ for an additional $24 \mathrm{~h}$. As shown in Figure 9a, in Western blotting analyses, curcumin enhanced, as expected, the abundance of GCLc and GCLm in passaged HSCs (Zheng, ${ }^{21}$ no. 7416). Pretreatment with the PPAR $\gamma$ antagonist, PD68235, dramatically abrogated the stimulatory effect, suggesting that the process might require activation of PPAR $\gamma$. To verify the role of PPAR $\gamma$ activation in the induction of $\mathrm{gclc}$ and $\mathrm{gclm}$ expression, passaged HSCs were stimulated with the natural PPAR $\gamma$ agonist, $\mathrm{PGJ}_{2}$, at various concentrations for $24 \mathrm{~h}$. Results from real-timePCR (Figure 9b) and Western blotting analyses (Figure 9c) confirmed that activation of PPAR $\gamma$ by $\mathrm{PGL}_{2}$ induced $g c l c$ and $\mathrm{gclm}$ expression in a dose-dependent manner. Taken together, these results revealed that activation of PPAR $\gamma$ induced $g c l c$ and gclm expression in activated HSCs in vitro. 

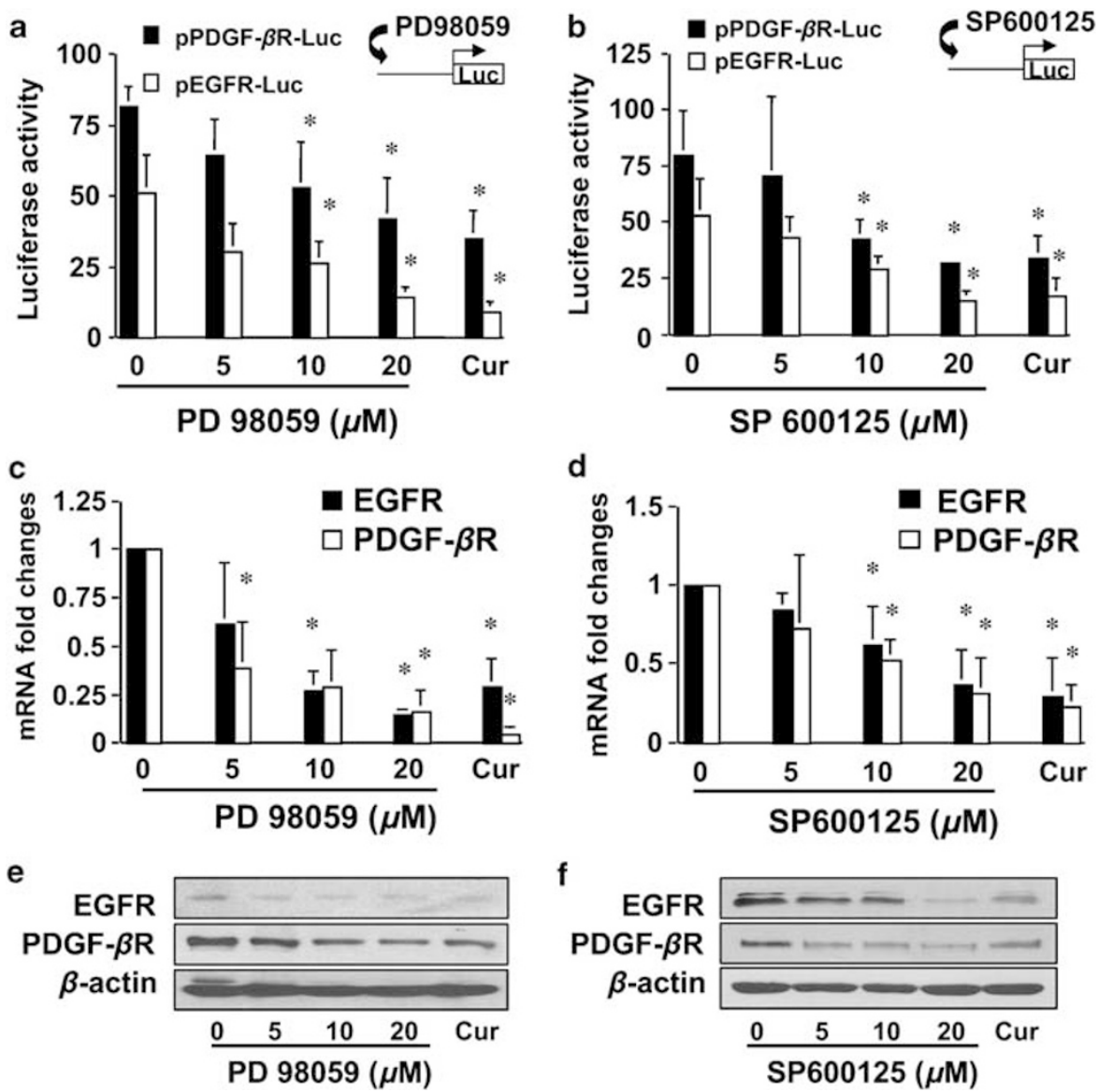

Figure 7 The inhibition of ERK or JNK activity reduced $p d g f-\beta r$ and egfr expression in activated HSCs in vitro. Cultured HSCs in DMEM with 10\% of FBS were treated with curcumin $(20 \mu \mathrm{M})$, or the ERK inhibitor PD98059 (a, c, and e), or the JNK inhibitor SP600125 (b, d, and f), at the indicated doses for $24 \mathrm{~h}$. (a and $\mathbf{b}$ ). Luciferase assays of cells transfected with pPDGF- $\beta$ R-Luc, or pEGFR-Luc. Luciferase activities were expressed as relative units after $\beta$-galactosidase normalization $(n=6) .{ }^{*} P<0.05$ vs the un-treated control (the corresponding first column on the left). The floating schema denotes the pPDGF- $\beta$ R-Luc, or pEGFR-Luc, luciferase reporter construct in use and the application of a kinase inhibitor to the system; (c and d) real-time PCR analyses of the mRNA levels of PDGF- $\beta$ R or EGFR. GAPDH was used as an invariant control for calculating fold changes of target mRNA $(n=3)$. ${ }^{\star} P<0.05$ vs the untreated control (the corresponding first column on the left); (e and $\mathbf{f}$ ) Western blotting analyses of the abundance of PDGF- $\beta$ R or EGFR. $\beta$-Actin was used as an invariant control for equal loading. Representative result is shown from three independent experiments.

\section{DISCUSSION}

We previously proposed that there might exist an antagonistic relationship between activation of the signaling pathways for growth factors, including PDGF and EGF, and activation of PPAR $\gamma$ in HSC, that is, activation of the signaling pathways for PDGF and EGF reduces the activity of PPAR $\gamma$ by suppressing PPAR $\gamma$ gene expression during HSC activation, whereas activation of PPAR $\gamma$ results in interruption of the signaling pathways, leading to inhibition of HSC activation. ${ }^{20,22}$ Our prior results supported the proposal and demonstrated that activation of PDGF or EGF signaling suppressed gene expression of PPAR $\gamma$ in activated HSCs in vitro. The current study was aimed at elucidating the effect of PPAR $\gamma$ activation on the PDGF or EGF signaling in HSC, and at elucidating the underlying mechanisms. In this report, we demonstrated that activation of PPAR $\gamma$ by curcumin or its agonist interrupted the PDGF or EGF signaling pathways by reducing the phosphorylation levels of PDGF- $\beta$ R and EGFR, and suppressing $p d g f-\beta r$ and egfr expression. Further experiments revealed that activation of PPAR $\gamma$ induced expression of GCL genes and stimulated synthesis of GSH, leading to suppression of $p d g f-\beta r$ and egfr expression.

The tyrosine kinase receptors of EGFR and PDGFR have received a great deal of attention as potential therapeutic targets for treatment of hepatic fibrosis, ${ }^{31,32}$ as these receptors have been shown to play key roles in hepatic fibrogenesis. ${ }^{3-6}$ As expected, exogenous PDGF and EGF stimulated cell proliferation of HSC in a dose-dependent manner, which was diminished by curcumin (Figure 1). However, different strategies of treatment with curcumin, that is, pretreatment or simultaneous treatment, showed different inhibitory efficiencies. Pretreatment with curcumin strengthened the inhibitory effect on cell proliferation. This discrepancy in the inhibitory efficiencies indicated that the inhibitory effect of curcumin on PDGF- or EGF-stimulated cell proliferation might not result from direct interactions between curcumin 
a

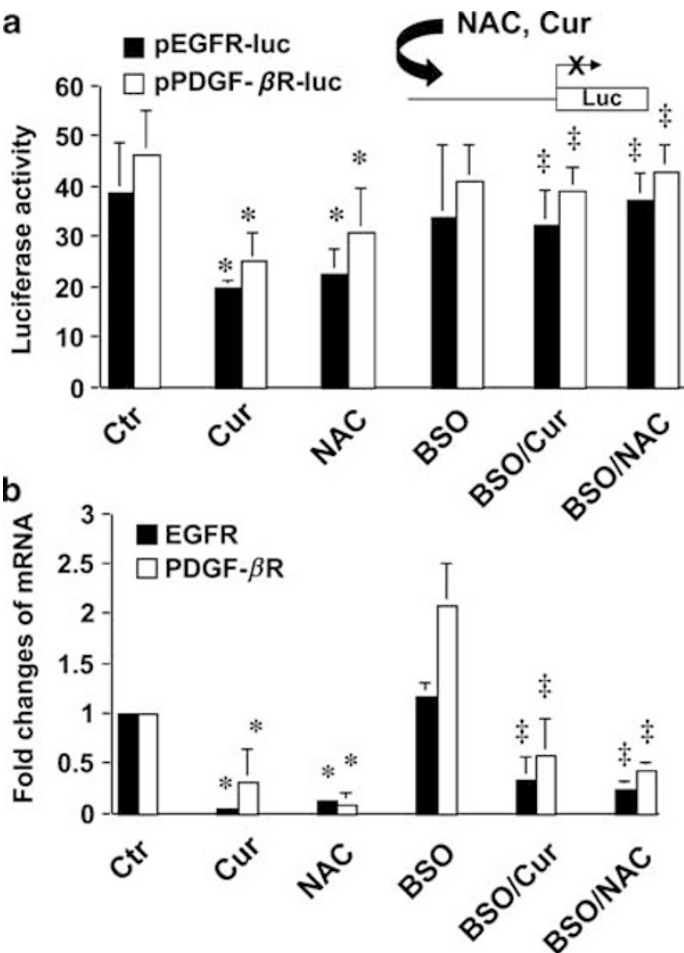

C

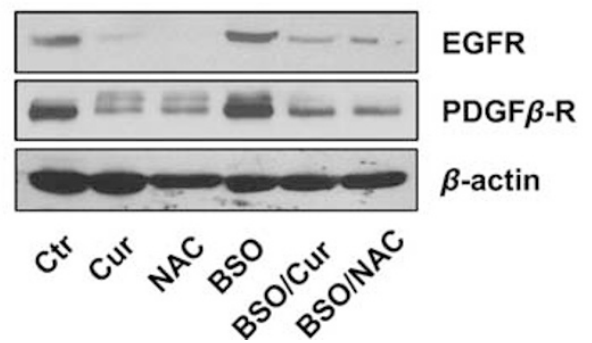

Figure 8 The inhibition of de novo GSH synthesis eliminated the inhibitory effect of curcumin on pdgf- $\beta r$ and egfr expression in activated HSCS in vitro. HSCs in DMEM with $10 \%$ of FBS were treated for $24 \mathrm{~h}$ with curcumin $(20 \mu \mathrm{M})$ or NAC $(5 \mathrm{mM})$ with or without the pre-exposure to BSO $(0.25 \mathrm{mM})$ for $1 \mathrm{~h}$. Values were means \pm s.d. $(n \geq 3)$. ${ }^{\star} P<0.05$, vs cells with no treatment (the corresponding first column on the left); ${ }^{\ddagger} P<0.05$, vs cells treated with curcumin, or NAC, only (the corresponding second or the third column on the left). (a) Luciferase assays of cells transfected with pPDGF- $\beta$ R-Luc, or pEGFR-Luc. Luciferase activities were expressed as relative units after $\beta$-galactosidase normalization $(n=6)$. The floating schema denotes the pPDGF- $\beta$ R-Luc, or pEGFR-Luc, luciferase reporter construct in use and the application of NAC or curcumin to the system; (b) real-time PCR analyses of the mRNA levels of PDGF- $\beta$ R, or EGFR. GAPDH was used as an invariant control for calculating fold changes of target mRNA $(n=3)$; (c) Western blotting analyses of the abundance of PDGF- $\beta$ R, or EGFR. $\beta$-Actin was used as an invariant control for equal loading. Representative result is shown from three independent experiments.

and PDGF or EGF. Further experiments revealed that curcumin reduced the abundance of PDGF- $\beta$ R and EGFR in activated HSCs after a 24 -h treatment (Figures $2-4$ ). In addition, curcumin significantly and rapidly reduced phosphorylation levels of PDGF- $\beta$ R and EGFR (Figure 5), which reached its peak within 10-20 min. These observations could partially explain the discrepancy in the inhibitory efficiencies. a
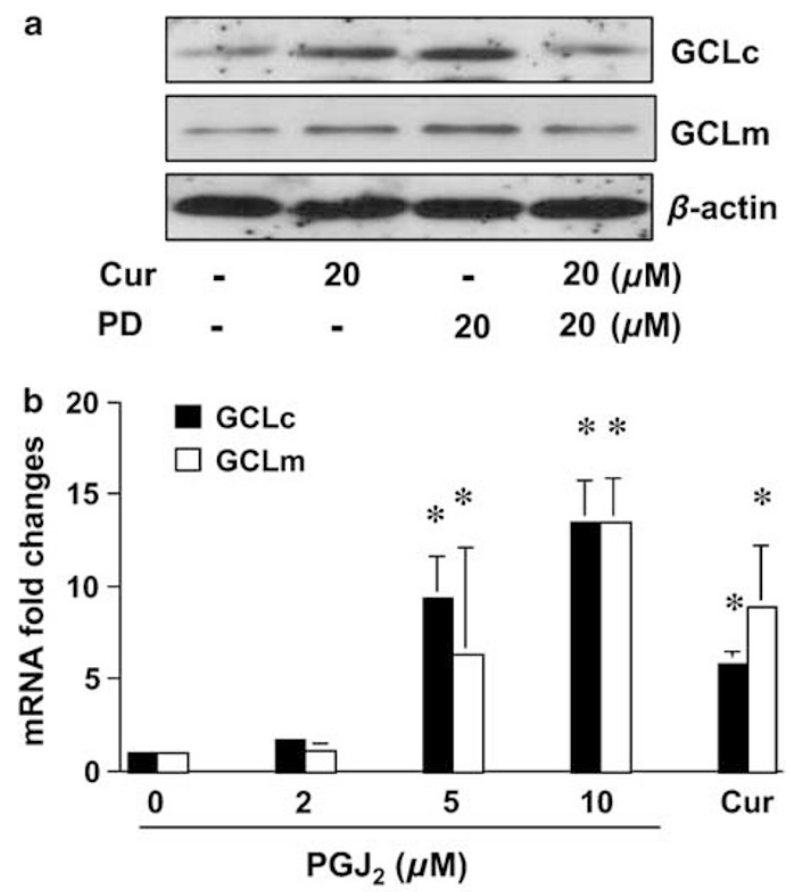

C

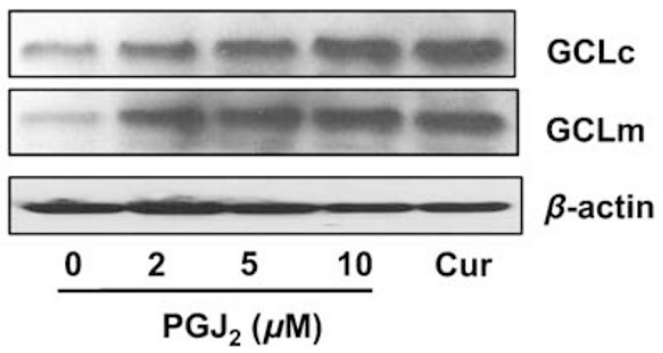

Figure 9 The activation of PPAR $\gamma$ induced $g c / c$ and $g c / m$ expression in activated HSCs in vitro. (a) Cultured HSCs in DMEM with $10 \%$ of FBS were pretreated with or without the PD68235 $(20 \mu \mathrm{M})$, a specific PPAR $\gamma$ antagonist, for $1 \mathrm{~h}$ prior to the addition of curcumin at the indicated concentrations for an additional $24 \mathrm{~h}$. Western blotting analyses of GCLC and GCLm. $\beta$-Actin was used as an invariant control for equal loading. Representative was shown from three independent experiments. (b and $\mathbf{c}$ ) Cultured HSCs in DMEM with $10 \%$ of FBS were treated with curcumin $(20 \mu \mathrm{M})$ or $\mathrm{PGJ}_{2}$ at the indicated concentrations for $24 \mathrm{~h}$. (b) Real-time PCR analyses of the mRNA levels of GCLC and GCLm. GAPDH was used as an invariant control for calculating fold changes of target mRNA $(n=3)$. ${ }^{*} P<0.05$ vs the untreated control (the corresponding first column on the left); (c) Western blotting analyses of the abundance of GCLC and $\mathrm{GCLm}$. $\beta$-Actin was used as an invariant control for equal loading. Representative result is shown from three independent experiments.

The activation of PDGF and EGF signaling was receptordependent. Simultaneous treatment with curcumin rapidly interrupted PDGF and EGF signaling by blocking tyrosine phosphorylation of PDGF- $\beta$ R and EGFR. It was an instantaneous, but short-term, action. The interruption of PDGF and EGF signaling by suppression of $p d g f-\beta r$ and egfr expression might require much longer time, such as several hours. Therefore, PDGF and EGF could activate their signaling and stimulate cell proliferation during the period of time after the peak of the dephosphorylation of the receptors and before 
the significant reduction in the abundance of the receptors. Therefore, in the case of simultaneous treatment with curcumin plus PDGF or EGF, the stimulatory effects of PDGF and EGF on cell proliferation were delayed and attenuated, but still executed. In great contrast, pretreatment with curcumin for $24 \mathrm{~h}$ resulted in significant reduction in the abundance of PDGF- $\beta$ R and EGFR. In this case, there might not be enough PDGF- $\beta$ R and EGFR for binding to PDGF and EGF to initiate their signaling at the very beginning. Therefore, pretreatment with curcumin could result in a more efficient inhibitory effect on cell proliferation. It bears notice that the serum-depleted medium was used in these experiments to eliminate the influence of unidentified mitogenic compounds present in serum or serum-derived medium additives. In addition, serum rich media, for example, media with $10 \%$ FBS, contain enough growth factors, including PDGF and EGF, for stimulating cell proliferation, which could interfere with and attenuate the stimulatory effects of exogenous PDGF or EGF. ${ }^{33}$

Recent studies have demonstrated that pro-adipogenic factors inhibit HSC activation. ${ }^{34}$ Adipocyte differentiation is positively stimulated by PPAR $\gamma,{ }^{35,36}$ and negatively regulated by PDGF and EGF. ${ }^{37,38}$ PPAR $\gamma$ stimulated adipogenesis and inhibited HSC activation. ${ }^{34-36}$ Adipogenic regulation might be critical for HSCs to maintain and restore the quiescent phenotypes. ${ }^{34}$ To determine the relationship between PPAR $\gamma$ activation and the growth factors in regulating adipogenesis, it was previously demonstrated that PPAR $\gamma$ transcriptional activity was reduced by PDGF through phosphorylation of PPAR $\gamma$ by MAP kinases. ${ }^{39}$ We recently reported that PDGF and EGF suppressed gene expression of PPAR $\gamma$ in cultured HSCs. ${ }^{22}$ The interruption of the PDGF and EGF signaling pathways by curcumin stimulated gene expression of PPAR $\gamma$ in HSC in vitro. ${ }^{22}$ The inhibition of ERK and JNK activity played a critical role in the induction of gene expression of PPAR $\gamma$ in HSCs. ${ }^{22}$ On the other hand, our preliminary results suggested that activation of $\operatorname{PPAR} \gamma$ might, in turn, inhibit ERK and JNK activity in cultured HSCs (data not shown here). The current studies further evaluated the relationship between PPAR $\gamma$ activation and PDGF and EGF signaling in activated HSCs in vitro. Our results indicated that activation of PPAR $\gamma$ interrupted PDGF and EGF signaling by reducing the level of the phosphorylation of PDGF- $\beta$ R and EGFR, and by suppressing gene expression of the receptors. Our results collectively demonstrated the existence of the antagonistic relationship between activation of PPAR $\gamma$ and stimulation of PDGF and EGF signaling in HSCs.

Curcumin has been studied as a therapeutic or preventive candidate because of its antioxidative and anti-inflammatory properties. ${ }^{17,40}$ In phase I clinical studies, curcumin with doses up to 3600-8000 mg daily for 4 months did not result in discernible toxicities, except mild nausea and diarrhea. ${ }^{41}$ The cytotoxicity of curcumin to cultured HSCs was previously evaluated. ${ }^{11}$ Based on results from LDH release assays, trypan blue-exclusion assays and a rapid recovery of cell proliferation after withdrawal of curcumin, it was concluded that curcumin up to $100 \mu \mathrm{M}$ was not toxic to cultured HSCs. The working concentration of curcumin used in this study was $20 \mu \mathrm{M}$, which is in the range of concentrations used by most of others. This concentration is much higher than those observed in blood and/or tissues of human and animals. ${ }^{42,43}$ Systemic bioavailability of curcumin is relatively low. ${ }^{44}$ Curcumin concentrations in human plasma could reach up to $2 \mu \mathrm{M}$ after oral intake of very high amounts of curcumin. ${ }^{45}$ Although higher concentrations of curcumin in blood might be possible, depending on the actual composition of food, ${ }^{46}$ most pharmacokinetic studies in humans point out that only low micromolar levels of curcumin can be found in blood. We recently observed that oral administration of curcumin at $200 \mathrm{mg} / \mathrm{kg}$ body weight significantly reduced the levels of the transcript and protein of PDGF- $\beta$ R and EGFR in the liver, inhibited HSC activation, and protected the liver from injury caused by $\mathrm{CCl}_{4}{ }^{15}$ It bears emphasis that because the in vivo system is multi-factorial, directly extrapolating in vitro conditions and results, for example, effective concentrations, to the in vivo system might be misleading.

Increasing evidence has demonstrated that oxidative stress promotes HSC activation and collagen production and plays an important role in the pathogenesis of liver fibrosis. ${ }^{47-49}$ Mammalian cells respond to oxidative stress through antioxidant defense, which includes antioxidant enzymes and non-enzyme molecules. GSH is the predominant lowmolecular-weight thiol and the most important non-enzyme antioxidant. GSH effectively protects cells against damage caused by oxidative stress, which might prevent diseases associated with oxidative stress. ${ }^{50}$ We previously showed that curcumin elevated the level of cellular GSH in cultured HSC by increasing GCL activity through induction of expression of the two subunits of GCL. ${ }^{21}$ We further demonstrated in this report that blockade of the synthesis of GSH attenuated the effects of curcumin on the suppression of $p d g f-\beta r$ and egfr expression in HSCs (Figure 8). The process was mediated by activation of PPAR $\gamma$ through induction of gene expression of GCL (Figure 9). Our results are consistent with other prior observations. In many cell types, gene expression of PDGF$\beta \mathrm{R}$ and EGFR is associated with increase in oxidative stress, which might represent pathophysiological determinants. ${ }^{51-53}$ Additional experiments are necessary to elucidate the underlying mechanisms by which oxidative stress regulates $p d g f-\beta r$ and egfr expression in HSCs.

Based on prior and current observations, a simplified model is proposed in Figure 10 to describe the mechanisms by which the curcumin activation of PPAR $\gamma$ interrupts PDGF and EGF signaling. Curcumin rapidly interrupts PDGF- $\beta$ R and EGFR signaling in activated HSCs by reducing the phosphorylation levels of PDGF- $\beta$ R and EGFR, as well as of their downstream signaling inter-mediators ERK and JNK. This instant action causally stimulates gene expression ${ }^{22}$ and activity of PPAR $\gamma,{ }^{39}$ which critically lead to attenuation of oxidative stress by inducing gene expression of GCL and 


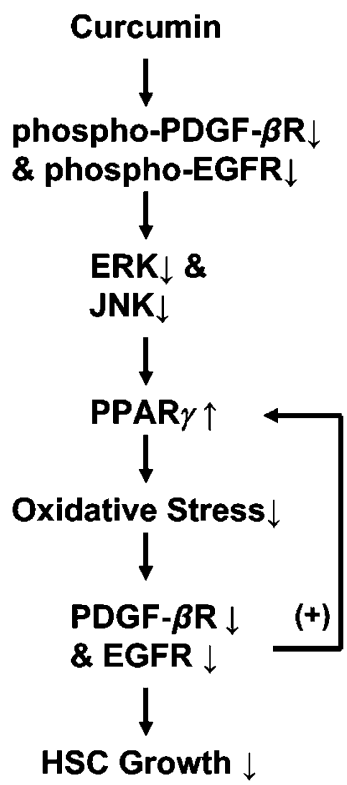

Figure 10 Schema of the underlying mechanism of curcumin in the interruption of PDGF and EGF signaling in activated HSC in vitro. Curcumin rapidly interrupts PDGF- $\beta$ R and EGFR signaling in activated HSCs by reducing the phosphorylation levels of PDGF- $\beta$ R and EGFR, as well as of their downstream signaling inter-mediators ERK and JNK. This instant action causally stimulates gene expression and its activity of PPAR $\gamma$, which critically leads to attenuation of oxidative stress by induction of gene expression of GCL and elevation of the level of cellular GSH. The actions of curcumin, including activation of PPAR $\gamma$ and elevation of GSH contents, collectively result in suppression of $p d g f-\beta r$ and egfr expression, leading to long-term interruption of PDGF- $\beta$ R and EGFR signaling and inhibition of cell proliferation.

elevating the level of cellular GSH. The actions of curcumin, including activation of PPAR $\gamma$ and elevation of GSH contents, collectively result in suppression of $p d g f-\beta r$ and egfr expression, leading to long-term interruption of PDGF- $\beta \mathrm{R}$ and EGFR signaling, and inhibition of cell proliferation. In addition, interruption of signaling for PDGF and EGF antagonistically induces gene expression of $\operatorname{PPAR} \gamma{ }^{22}$ It bears emphasis that the underlying mechanisms are certainly more complex than what described here. It remains unclear what factors are involved in the instant curcumin reduction of the phosphorylation levels of PDGF- $\beta$ R and EGFR, and what transcription factors mediate suppression of $p d g f-\beta r$ and $e g f r$ expression in HSC. In addition, our results do not exclude possible involvement of any other mechanisms in the curcumin interruption of PDGF and EGF signaling. In summary, these results support our original hypothesis that enhancement of PPAR $\gamma$ activity by curcumin might result in interruption of the signaling pathways for PDGF and EGF. These results provide novel insights into the mechanisms of curcumin in the inhibition of cell proliferation and activation of HSCs.

\section{ACKNOWLEDGEMENT}

The work was supported by the grant RO1 DK 047995 from NIH/NIDDK to A Chen.
1. Bataller R, Brenner DA. Liver fibrosis. J Clin Invest 2005;115:209-218.

2. Friedman SL. Stellate cells: a moving target in hepatic fibrogenesis. Hepatology 2004;40:1041-1043.

3. Wong L, Yamasaki G, Johnson RJ, et al. Induction of beta-plateletderived growth factor receptor in rat hepatic lipocytes during cellular activation in vivo and in culture. J Clin Invest 1994;94:1563-1569.

4. Bachem MG, Riess U, Gressner AM. Liver fat storing cell proliferation is stimulated by epidermal growth factor/transforming growth factor alpha and inhibited by transforming growth factor beta. Biochem Biophys Res Commun 1989;162:708-714.

5. Komuves LG, Feren A, Jones AL, et al. Expression of epidermal growth factor and its receptor in cirrhotic liver disease. J Histochem Cytochem 2000;48:821-830.

6. Pinzani $M$, Milani $S$, Herbst $H$, et al. Expression of platelet-derived growth factor and its receptors in normal human liver and during active hepatic fibrogenesis. Am J Pathol 1996;148:785-800.

7. Galli A, Crabb D, Price D, et al. Peroxisome proliferator-activated receptor gamma transcriptional regulation is involved in plateletderived growth factor-induced proliferation of human hepatic stellate cells. Hepatology 2000;31:101-108.

8. Marra F, Efsen E, Romanelli RG, et al. Ligands of peroxisome proliferator-activated receptor gamma modulate profibrogenic and proinflammatory actions in hepatic stellate cells. Gastroenterology 2000;119:466-478.

9. Miyahara T, Schrum L, Rippe R, et al. Peroxisome proliferator-activated receptors and hepatic stellate cell activation. J Biol Chem 2000;275:35715-35722.

10. Hazra S, Xiong S, Wang J, et al. Peroxisome proliferator-activated receptor gamma induces a phenotypic switch from activated to quiescent hepatic stellate cells. J Biol Chem 2004;279:11392-11401.

11. $\mathrm{Xu} \mathrm{J,} \mathrm{Fu} \mathrm{Y,} \mathrm{Chen} \mathrm{A.} \mathrm{Activation} \mathrm{of} \mathrm{peroxisome} \mathrm{proliferator-activated}$ receptor-gamma contributes to the inhibitory effects of curcumin on rat hepatic stellate cell growth. Am J Physiol Gastrointest Liver Physiol 2003;285:G20-G30.

12. Pinzani $M$, Gesualdo $L$, Sabbah GM, et al. Effects of platelet-derived growth factor and other polypeptide mitogens on DNA synthesis and growth of cultured rat liver fat-storing cells. J Clin Invest 1989;84:1786-1793.

13. Citri A, Yarden Y. EGF-ERBB signalling: towards the systems level. Nat Rev Mol Cell Biol 2006;7:505-516.

14. Perona R. Cell signalling: growth factors and tyrosine kinase receptors. Clin Transl Oncol 2006;8:77-82.

15. Fu $\mathrm{Y}, \mathrm{Zheng} \mathrm{S}$, Lin J, et al. Curcumin protects the rat liver from $\mathrm{CCl} 4$-caused injury and fibrogenesis by attenuating oxidative stress and suppressing inflammation. Mol Pharmacol 2008;73:399-409.

16. Nanji AA, Jokelainen K, Tipoe GL, et al. Curcumin prevents alcoholinduced liver disease in rats by inhibiting the expression of NF-kappa B-dependent genes. Am J Physiol Gastrointest Liver Physiol 2003;284:G321-G327.

17. O'Connell MA, Rushworth SA. Curcumin: potential for hepatic fibrosis therapy? Br J Pharmacol 2008;153:403-405.

18. Park EJ, Jeon $\mathrm{CH}, \mathrm{Ko} \mathrm{G}$, et al. Protective effect of curcumin in rat liver injury induced by carbon tetrachloride. J Pharm Pharmacol 2000;52:437-440.

19. Zheng $\mathrm{S}$, Chen A. Activation of PPARgamma is required for curcumin to induce apoptosis and to inhibit the expression of extracellular matrix genes in hepatic stellate cells in vitro. Biochem J 2004;384: 149-157.

20. Zheng S, Chen A. Curcumin suppresses the expression of extracellular matrix genes in activated hepatic stellate cells by inhibiting gene expression of connective tissue growth factor. Am J Physiol Gastrointest Liver Physiol 2006;290:G883-G893.

21. Zheng $S$, Yumei $F$, Chen A. De novo synthesis of glutathione is a prerequisite for curcumin to inhibit hepatic stellate cell (HSC) activation. Free Radic Biol Med 2007;43:444-453.

22. Zhou Y, Zheng S, Lin J, et al. The interruption of the PDGF and EGF signaling pathways by curcumin stimulates gene expression of PPARgamma in rat activated hepatic stellate cell in vitro. Lab Invest 2007;87:488-498.

23. Chen A, Davis BH. The DNA binding protein BTEB mediates acetaldehyde-induced, jun $\mathrm{N}$-terminal kinase-dependent alphal(I) collagen gene expression in rat hepatic stellate cells. Mol Cell Biol 2000;20:2818-2826. 
24. Schmittgen TD, Zakrajsek BA, Mills AG, et al. Quantitative reverse transcription-polymerase chain reaction to study mRNA decay: comparison of endpoint and real-time methods. Anal Biochem 2000;285:194-204.

25. Ballagi AE, Ishizaki A, Nehlin JO, et al. Isolation and characterization of the mouse PDGF beta-receptor promoter. Biochem Biophys Res Commun 1995;210:165-173.

26. Nishi H, Nishi KH, Johnson AC. Early growth response-1 gene mediates upregulation of epidermal growth factor receptor expression during hypoxia. Cancer Res 2002;62:827-834.

27. Davis $\mathrm{BH}, \mathrm{Chen} \mathrm{A}$, Beno DW. Raf and mitogen-activated protein kinase regulate stellate cell collagen gene expression. J Biol Chem 1996;271:11039-11042.

28. Mansour SJ, Matten WT, Hermann AS, et al. Transformation of mammalian cells by constitutively active MAP kinase kinase. Science 1994;265:966-970.

29. Cotgreave IA. N-acetylcysteine: pharmacological considerations and experimental and clinical applications. Adv Pharmacol 1997;38: 205-227.

30. Griffith OW. Mechanism of action, metabolism, and toxicity of buthionine sulfoximine and its higher homologs, potent inhibitors of glutathione synthesis. J Biol Chem 1982;257:13704-13712.

31. Borkham-Kamphorst E, Herrmann J, Stoll D, et al. Dominant-negative soluble PDGF-beta receptor inhibits hepatic stellate cell activation and attenuates liver fibrosis. Lab Invest 2004;84:766-777.

32. Borkham-Kamphorst E, Stoll D, Gressner AM, et al. Inhibitory effect of soluble PDGF-beta receptor in culture-activated hepatic stellate cells. Biochem Biophys Res Commun 2004;317:451-462.

33. $\mathrm{Fu} \mathrm{Y,} \mathrm{Chen} \mathrm{A.} \mathrm{The} \mathrm{phytochemical} \mathrm{(-)-epigallocatechin} \mathrm{gallate}$ suppresses gene expression of epidermal growth factor receptor in rat hepatic stellate cells in vitro by reducing the activity of Egr-1. Biochem Pharmacol 2006;72:227-238.

34. Tsukamoto $\mathrm{H}$, She $\mathrm{H}$, Hazra $\mathrm{S}$, et al. Anti-adipogenic regulation underlies hepatic stellate cell transdifferentiation. J Gastroenterol Hepatol 2006;21(Suppl 3):S102-S105.

35. Farmer SR. Regulation of PPARgamma activity during adipogenesis. Int J Obes (Lond) 2005;29(Suppl 1):S13-S16.

36. Nedergaard J, Petrovic N, Lindgren EM, et al. PPARgamma in the control of brown adipocyte differentiation. Biochim Biophys Acta 2005;1740:293-304.

37. Artemenko Y, Gagnon A, Aubin D, et al. Anti-adipogenic effect of PDGF is reversed by PKC inhibition. J Cell Physiol 2005;204: 646-653.

38. Hanlon PR, Cimafranca MA, Liu X, et al. Microarray analysis of early adipogenesis in $\mathrm{C} 3 \mathrm{H} 10 \mathrm{~T} 1 / 2$ cells: cooperative inhibitory effects of growth factors and 2, 3, 7, 8-tetrachlorodibenzo-p-dioxin. Toxicol Appl Pharmacol 2005;207:39-58.

39. Camp HS, Tafuri SR. Regulation of peroxisome proliferator-activated receptor gamma activity by mitogen-activated protein kinase. J Biol Chem 1997;272:10811-10816.

40. Bright JJ. Curcumin and autoimmune disease. Adv Exp Med Biol 2007;595:425-451.

41. Hsu CH, Cheng AL. Clinical studies with curcumin. Adv Exp Med Biol 2007;595:471-480

42. Ammon HP, Wahl MA. Pharmacology of Curcuma longa. Planta Med 1991;57:1-7.

43. Pan $\mathrm{MH}$, Huang TM, Lin JK. Biotransformation of curcumin through reduction and glucuronidation in mice. Drug Metab Dispos 1999;27:486-494.

44. Sharma RA, McLelland HR, Hill KA, et al. Pharmacodynamic and pharmacokinetic study of oral Curcuma extract in patients with colorectal cancer. Clin Cancer Res 2001;7:1894-1900.

45. Garcea G, Jones DJ, Singh $R$, et al. Detection of curcumin and its metabolites in hepatic tissue and portal blood of patients following oral administration. Br J Cancer 2004;90:1011-1015.

46. Sharma RA, Gescher AJ, Steward WP. Curcumin: the story so far. Eur J Cancer 2005;41:1955-1968.

47. Greenwel P, Dominguez-Rosales JA, Mavi G, et al. Hydrogen peroxide: a link between acetaldehyde-elicited alpha1(I) collagen gene upregulation and oxidative stress in mouse hepatic stellate cells. Hepatology 2000;31:109-116.

48. Lee KS, Buck M, Houglum K, et al. Activation of hepatic stellate cells by TGF alpha and collagen type $\mathrm{I}$ is mediated by oxidative stress through c-myb expression. J Clin Invest 1995;96:2461-2468.

49. Tsukamoto $H$, Rippe $R$, Niemela $O$, et al. Roles of oxidative stress in activation of Kupffer and Ito cells in liver fibrogenesis. J Gastroenterol Hepatol 1995;10(Suppl 1):S50-S53.

50. Sueoka N, Suganuma M, Sueoka E, et al. A new function of green tea: prevention of lifestyle-related diseases. Ann N Y Acad Sci 2001:928:274-280.

51. Allard J, Buleon M, Cellier E, et al. ACE inhibitor reduces growth factor receptor expression and signaling but also albuminuria through B2-kinin glomerular receptor activation in diabetic rats. Am J Physiol Renal Physiol 2007;293:F1083-F1092.

52. Ingram JL, Bonner JC. EGF and PDGF receptor tyrosine kinases as therapeutic targets for chronic lung diseases. Curr Mol Med 2006;6:409-421.

53. Goldkorn T, Ravid T, Khan EM. Life and death decisions: ceramide generation and EGF receptor trafficking are modulated by oxidative stress. Antioxid Redox Signal 2005;7:119-128. 